\title{
TECHNOLOGY AND ENTREPRENEURIAL ORIENTATION AT THE ORGANISATIONAL LEVEL IN THE JOHANNESBURG AREA
}

Author:

Boris Urban

\section{Affiliation:}

${ }^{1}$ Wits Business

School, University of

Witwatersrand,

South Africa

\section{Correspondence to:}

Boris Urban

email:

Boris.urban@wits.ac.za

\section{Postal address:}

Wits Business

School, University of

Witwatersrand, PO Box 98

Wits 2050, South Africa

\section{Keywords:}

Entrepreneurship;

technology; environment;

hostility; dynamism

\section{Dates:}

Received: 24 April 2009

Accepted: 18 Jan. 2010

Published: 25 May 2010

How to cite this article:

Urban, B. (2010). Technology and entrepreneurial

orientation at the

organisational level in the

Johannesburg area. $S A$

Journal of Human Resource

Management/SA Tydskrif vir

Menslikehulpbronbestuur,

8(1), Art. \#212, 9 pages. DOI:

10.4102/sajhrm.v8i1.212

This article is available

at:

http://www.sajhrm.co.za

(c) 2010. The Authors.

Licensee: OpenJournals

Publishing. This work

is licensed under the

Creative Commons

Attribution License.

\begin{abstract}
Orientation: The 21st century is tilting towards an economy that is primarily driven by technology and knowledge, where entrepreneurs have to recognise and anticipate high-technology opportunities so as to join the ranks of future entrepreneurial leaders.
\end{abstract}

Research purpose: This study examines entrepreneurship and its relation with technology, which is often conceptualised as entrepreneurial orientation (EO) and technology orientation (TO). The study is further contextualised by measuring environmental dynamism and hostility.

Motivation for the study: Despite the weight of positive empirical findings and observations that $\mathrm{EO}$ and $\mathrm{TO}$ are strategic imperatives, there is a danger that firms in Africa are lagging behind and subsequently a study of this nature aids in understanding these imperatives.

Research design, approach and method: A survey is used to collect data from a population of diverse businesses in the Johannesburg area $(n=1600)$, yielding a sample of 236 firms. Instruments were subjected to principal component factor analysis and descriptive statistics were calculated. The hypotheses were tested using correlational analysis, with their significance reported in terms of Pearson correlation coefficients.

Main finding: Findings reveal significant correlations between EO and environment hostility and dynamism, but not between EO and TO.

Practical and managerial implications: The study offers some solutions towards understanding how TO and EO may promote firm innovation, which encourages the diffusion, adoption and application of the very latest technologies. This is particularly relevant in cases where a lot of potential exists in developing countries to 'import and adapt' technologies developed in industrialised countries.

Contribution of study: Research on firm innovation in the African context may be considered valuable, as very few empirical studies that have been conducted previously focus on innovation and technology in the context of an emerging country.

\section{INTRODUCTION}

Entrepreneurship and its relation to technology and innovation are studied extensively within organisations (Bosma, Jones, Autio \& Levie, 2007; Foba \& De Villiers, 2007; Lee \& Wong, 2004). Recent studies have advocated integrating innovation and technology at organisations where links have been established with firm performance (Bhuian, Menguc \& Bell, 2005; Guan \& Liu, 2007). Firms which have adopted a technology orientation (TO) pursue advances in technology and innovations, and investments are made in discontinuous innovations and disruptive technologies with the assumption that entire new markets will emerge (Schindehutte, Morris \& Kocak, 2008).

In emerging economies, such as South Africa, where growth is often the primary goal of organisations, innovation in firms can be particularly critical for firm profitability and survival (Antoncicm \& Hisrich, 2001). The 21st century is tilting towards an economy primarily driven by technology and knowledge, where entrepreneurs have to recognise and anticipate high-technology opportunities so as to join the ranks of future entrepreneurial leaders (Kourilsky \& Walstad, 2002).

Technology and firm innovation can not only create value but can aid in the international expansion process which many firms in emerging countries are now undertaking. A strong technology and entrepreneurial orientation (EO) at the firm level can provide the necessary competitive advantage for companies in emerging countries to compete globally (Rwigema, Urban \& Venter, 2008).

Not only are organisations seeking to reorientate themselves to become strategically innovative (McGuigan \& Henderson, 2005), but previous literature and empirical findings point to entrepreneurial orientation as an important element in organisational and economic development. Entrepreneurship within organisations is a fundamental posture, instrumentally important to strategic innovation, particularly under shifting external environmental conditions (Knight, 1997). The EO construct is salient not only for large organisations, but also for small and medium-sized organisations in different stages of economic development and in varied cultural contexts. At the level of the organisation, entrepreneurship can provide direction to the company's entire operation, serves as an integral component of a firm's strategy and may serve as the core component of corporate strategy (Chen, He \& Jin, 2008; Guan \& Liu, 2007; Morris, Kuratko \& Covin, 2008). Entrepreneurial actions are the bedrock of entrepreneurial processes and behaviour.

These two dominant orientations, TO and EO, often termed strategic orientations at the firm level, provide the focus for this study. Since these orientations may be critical to the long-term survival 
of a firm (Stevenson, 1983), it is important to facilitate the empirical study of them. This paper moves in this direction by empirically testing the relationship between $\mathrm{EO}$ and $\mathrm{TO}$ However, simply examining the direct EO-TO relationship may provide an incomplete picture; it is necessary to understand how environmental factors might be linked with each orientation (Wang, 2008). Research suggests that a key part of a TO is the interaction of that strategy with the venture's external environment (Zahra \& Bogner, 1999). Moreover, EO is affected by and should fit the firm's particular environment. Consequently, in this present study, associations between EO and TO and environmental hostility and dynamism are hypothesised.

Despite the weight of positive empirical findings and observations that $\mathrm{EO}$ and $\mathrm{TO}$ are strategic imperatives (Antoncic, 2006; Autio, 2005; Goel, Gonzalez-Moreno \& SaezMartines, 2003), there is a danger that firms in Africa are lagging behind and subsequently a study of this nature aids in understanding these imperatives. Another reason for focusing on EO is that, although studies using the EO scale have often been replicated, the majority of research in entrepreneurship and technology has been conducted in the United States. As the relevance of international entrepreneurship is recognised (Jantunen, Puumalainen, Saarenketo \& Kylaheiko, 2005), the further investigation of EO and TO in the context of an emerging country seems justifiable.

\section{LITERATURE REVIEW}

\section{Entrepreneurship in firms}

The concept of entrepreneurship in corporations has been labelled in many different ways, which include intrapreneurship (Antoncic \& Hisrich, 2001; Kuratko, 2002), innovation entrepreneurship (Schumpeter, 1934), innovation management (Drucker, 1979), venture entrepreneurship (Tang \& Koveos, 2004), corporate intrapreneurship (Dess et al., 2003), strategic entrepreneurial posture (Covin \& Slevin, 1989) and internal corporate venturing (Hornsby, Kuratko \& Zahra, 2002).

Prior theory and research (Covin \& Slevin, 1989; Lumpkin \& Dess, 1996; Khandwalla, 1977; Miller \& Friesen, 1983) indicate that an EO is a key ingredient for organisational success, found to lead to increased performance (Kuratko, Ireland \& Hornsby, 2001; Wiklund \& Shepherd, 2003; Zahra \& Covin, 1995).

The concept of EO incorporates the firm-level processes, practices and decision-making styles of innovative firms (Lumpkin \& Dess, 1996). The theoretical basis of the EO construct lies in the assumption that all firms have an EO, even if levels of EO are very low. The current organisational research provides theoretical support for the EO construct, in both the fields of entrepreneurship and strategic management.

Extensive research confirms that EO has three dimensions - namely, innovativeness, risk taking and proactiveness (Covin \& Slevin, 1989, 1991, 1997; Kreiser, Marino \& Weaver 2002; Lumpkin \& Dess, 1996, 2001). Innovativeness is the fundamental posture of an entrepreneurial organisation in terms of developing new products or inventing new processes (Drucker, 1979; Schumpeter, 1934). Innovativeness as an attribute describes an organisation's willingness to add newness with added value. Risk-taking is associated with the willingness to commit significant resources to opportunities and to take calculated business risks (Aloulou \& Fayolle, 2005). Proactiveness is perseverance in ensuring that initiatives are implemented and is concerned with adaptability and tolerance of failure. These dimensions have been extensively documented and, according to Lumpkin and Dess (1996), all the dimensions are central to understanding the entrepreneurial process, although they may occur in different combinations, depending on the type of entrepreneurial opportunity the firm pursues.
Firms can be labelled as entrepreneurial only if they are simultaneously risk taking, innovative, and proactive (Covin, Green \& Slevin, 2006).

The extent to which each of these dimensions is useful for predicting the success of business may be contingent on industry environment and norms for EO can be expected to vary among industries. Lumpkin and Dess (1996) provide a contingency perspective on how environmental and organisational factors moderate, mediate, independently effect, or interact with EO to enhance firm performance. Typically, firms with an EO tend to outperform similar other organisational types in volatile environments (Knight, 1997).

The concept of EO is best understood as a complex mix of personal and situational factors. In addition to individual and firm differences, forces operating within other larger cultural contexts also determine levels of EO (Aloulou \& Fayolle, 2005; Urban, 2008).

\section{Environmental factors}

As with previous studies (Zahra \& Bogner, 1999), the present study emphasises environmental characteristics since these perceptions activate technology and entrepreneurial choices. Theory on the environment and its effect on high technology ventures and EO are well documented (Allen \& Stearns, 2004; Pownall \& Lawson, 2005). Specifically, the entrepreneur's perception of the external environment is expected to moderate the relationship between a technology venture's strategy and its financial performance (Zahra \& Bogner, 1999).

Three characteristic of the firm's external environment are discussed in the literature - namely, dynamism, hostility and heterogeneity. These characteristics reflect the objective conditions of an industry. The current study relies on two environmental dimensions, which is consistent with earlier research and theory building in the field of entrepreneurship, namely dynamism and hostility.

\section{Dynamism}

Dynamism reflects both the rate and unpredictability of change in the industry (Dess \& Beard, 1984). These changes result from the entry or exit of competitors, changes in customers' needs, and shifts in technological conditions. These changes create opportunities and threats for new ventures and compel their managers to act by building and leveraging technological resources. The unpredictability of these changes can also influence managers' investment in introducing new products and timing of their release (Porter, 1985).

\section{Hostility}

Hostility indicates an unfavourable business climate, such as intense competition for resources or market opportunities. Hostility arises from the existence of too many competitors, unfavourable supply conditions and strict regulation. Hostile environments are therefore resource-poor, lean environments; they lack the abundance of resources and capacity required to support a large number of ventures (Dess \& Beard, 1984; Zahra \& Bogner, 1999).

\section{Technology orientation}

Technology and innovation in entrepreneurial businesses is typically explained in a variety of ways. For instance, (1) by describing how early-stage entrepreneurs and established business owner-managers focus on the novelty (or unfamiliarity) of their products or services relative to customers' current experience (Bosma et al., 2007), or (2) by focusing on levels of innovativeness in entrepreneurial businesses as measured by the degree of competition faced by the business, or (3) by whether the owner-manager perceives that many, few or no 
other businesses offer similar products or services (Lee, Lee \& Penning, 2001).

Several types of new venture technology and innovation strategies are proposed in the literature, which include, but are not limited to:

- reactive imitation

- proactive localisation

- import substitution

- creative imitation

- early-market entry

- global niche and

- global innovation (Park \& Bae, 2004).

Strategic choice is of particular concern to technology-based ventures. For instance, they can adopt a product market strategy aimed at achieving growth in terms of revenues or a strategy where the objective is growth in the value of the technology with a view to an eventual exit through-sale to a strategic partner. A firm that is pursuing a strategy of differentiation based on innovative new product introductions might benefit from the human capital development through years of experience in technical jobs. Such experience would provide insights into technical advances that might enhance product features (Shrader \& Siegel, 2007). Developing new product technology and concern for technical expertise demonstrates the importance for technology-based new ventures to select strategies which they can successfully execute. It has also been suggested that true measures of success for technological entrepreneurs is the extent to which they are able to develop and bring to market radically innovative new products and/ or services. Radical innovations are important not only for the positive economic impact they typically create but also because they fundamentally change the behaviour of consumers.

Evaluating regional transformation through technological entrepreneurship, Venkataraman (2003) analyses how in a modern economy, universities and research and development laboratories are the incubators of novel technical ideas; it is no accident that areas around Boston and Silicon Valley have produced a significant amount of wealth. Infusing an enterprising spirit into technical endeavours and the promotion of inventive skills has been implemented as an impetus to promote technopreneurship in organisations (Lee \& Wong, 2004).

Both entrepreneurs and technopreneurs have similar qualities, such as determination, a willingness to take risk, the capacity to mobilise resources and perseverance to overcome setbacks. However, the capabilities required of technopreneurs go beyond this to include an expert knowledge of relevant technological developments together with innovative acumen (Wong, Cheung \& Venuvinod, 2005). It is a person's specific knowledge that is apparently the most important contributing factor in making a discovery and exploiting wealth-generating ideas (Fiet, Norton \& Clouse, 2002). Technopreneurs are an important group that can contribute significantly to raise national competitiveness, productivity and efficiency (Conway, 2008). In addition technopreneurs engage in go-to-market programmes through a global network of partners (Asia Africa Intelligence Wire, 2005).

Technopreneurism can be integrated into corporations through the formal strategy process. Foo and Foo (2000) conceptualise a model of corporations in Singapore acting to contribute towards configuring a unique environment congenial for sprouting technopreneurs. In Singapore, government built technological parks and research centres to encourage more firms to be involved in research and development activities; the government set aside billions of dollars in research funds and venture capital to encourage research in technologically related industries to become technopreneurs (Lee \& Wong, 2004).

The integration of entrepreneurship with strategy (i.e. technology orientation or TO) relies on the critical aspects of entrepreneurial strategy and a strategy for entrepreneurship (Kuratko \& Audretsch, 2009; Morris et al., 2008). It is conceivable that in many situations, a firm would have to excel along all or most of the dimensions of EO in order to achieve the ability to create superior value with regard to TO. This would indicate that there are significant associations between $\mathrm{EO}$ and $\mathrm{TO}$.

\section{Hypotheses}

The following hypotheses are formulated by drawing on the emerging body of knowledge. Given the lack of empirical evidence on $\mathrm{EO}$ and TO in terms of environmental dynamism and hostility, particularly in the context of an emerging country, instead of numerous hypotheses, the study formulates broadspanning hypotheses which allow for general explanations:

H1: A positive correlative relationship exists between EO and TO.

Entrepreneurship within organisations as a fundamental posture is conceived as EO, which is instrumentally important to a firm which adopts a TO, i.e. a firm that is characterised by discontinuous innovations and disruptive technologies with the assumption that entire new markets will emerge (Schindehutte et al., 2008).

H2: $\mathrm{TO}$ and EO is significantly associated with environmental dynamism and hostility. The greater the environmental dynamism and hostility, the greater the levels of TO and EO in a firm.

Myers and Marquis (1969) report that the more dynamic and hostile (i.e. competitive) the environment, the greater the need for innovation and the more likely that firms will be entrepreneurial, which in this case means increased levels of TO and EO. An environment characterised as dynamic creates opportunities and threats for new ventures, and managers react by investing in and leveraging technological resources. The unpredictability of these changes can also influence the firm's EO. Hostility is indicative of an unfavourable business climate, typically more competitive, where firms will need to adopt a TO and $\mathrm{EO}$ to remain competitive.

\section{RESEARCH DESIGN}

\section{Research approach}

A cross-sectional research design using a survey to generate quantitative responses was used. As TO and EO refer to managers' self-perception of a firm's strategic orientation, their self-perception should be closely related to the behaviour of the firm. Hence, as Wiklund (1999) argues, what is really measured is the chief executive officer's (CEO's) self-perception, which accordingly serves as a relevant proxy for measuring $\mathrm{EO}$ and TO.

Although regarded as a micro-level unit of analysis, the firm is an aggregate of different individuals and business activities, and the issues of relevance, size, size distributions and heterogeneity need to be acknowledged (Davidsson, 2004). Due to the variety of industry and firm heterogeneity anticipated in this present study, concerns of broad applicability versus perfect suitability for narrower groups were addressed. Measures that apply to all firms may at the same time apply to none, since they only capture a tiny fraction of each firm's manifestation of EO (Davidsson, 2004). To counteract such discrepancies the instruments were carefully operationalised and are described in detail.

Consistent with previous studies (Wiklund, 1999) control variables included the type of industry - based on the Standard Industrial Classification (SIC) index - firm age, and size of firm in employee numbers. Other intervening factors that may 
have moderated/mediated the relationship between the study variables are partially accounted for by measuring the direct effect of the environment.

\section{Research method}

\section{Measuring instruments}

The measures for $\mathrm{EO}, \mathrm{TO}$, environmental dynamism and hostility relied on previously established instruments. The EO dimensions have evolved from the ENTRESCALE, which was derived at by identifying the innovative and proactive disposition of managers at firms. This scale, initially developed by Khandwalla (1977) and refined by Miller and Friesen (1983) and Covin and Slevin (1989), has been found to be highly valid and reliable at cross-cultural levels (Knight, 1997). Although alternative EO conceptualisations are to be found (Brown, Davidsson \& Wiklund, 2001) and have demonstrated some usefulness, Davidsson (2004) suggests using the existing EO measure, which has the advantage of theoretical backing, a multidimensional construct and theoretically meaningful relationships established in previous studies, thus allowing for more refined knowledge to evolve. Subsequently, EO was measured along a seven-point bi-polar Likert scale, representing the three dimensions of innovation, proactiveness and risk taking. Respondents had to circle number 1 if the statement on the left-hand side of the scale best described their reaction to the item, or circle number 7 if the statement on the righthand side of the scale best described their reaction to the item. Moreover, an aggregated measure of EO can be useful when a differential relationship between the three dimensions and other variables under investigation are not expected (Kreiser $e t$ al., 2002), as was the case in this present study.

In order to operationalise a firm's level of TO, several different dimensions of technology which are generally considered to be mostrelevant toan organisation's technology strategy were used. To allow for meaningful comparisons with earlier work, a core set of questions based on technology and competitive strategies from the Panel Study of Entrepreneurial Dynamics (PSED) survey (Gartner, Shaver, Carter \& Reynolds, 2004) was selected. The PSED survey provides systematic, reliable data on those variables that explain and predict nascent entrepreneurship. Measures for TO were based on categories which divide firms into three types (Allen \& Stearns, 2004). These are: (1) first mover (a pioneering entrepreneur with a disruptive technology that creates a new paradigm), operationalised with surrogate variable: was the product/service available five years ago?; (2) practitioner (an entrepreneur who employs current technology to improve products, services or processes); (3) innovator (an incremental strategy whereby a entrepreneur modifies or improves existing technology).

For measures on the environment, the environmental dimensions of hostility and dynamism were selected due to the modest correlations reported between these two dimensions (Zahra, 1993), suggesting that unique aspects of the environment are captured with each dimension. Environmental dynamism (five items) and hostility (six items) were measured using a seven-point scale, in which 1 equals strongly agree and 7 equals strongly disagree with the statement. Respondents were asked to circle numbers 2 through 6 depending upon their best estimate of an intermediate position. Furthermore, respondents were asked to indicate the extent to which they agreed or disagreed with each statement as it applies to their business's principal industry (i.e. the industry that accounts for the largest percentage of their business's sales).

\section{Data collection and sampling}

Operationalisation of the empirical firm included firms that were legal entities - close corporations and private and public companies. A suitable sampling selection criterion was used where the minimum size criterion of firms sampled was set at 20 employees and the upper limit was set at 500 employees (here a single respondent still can report for an entire firm) which then overlaps with the criterion for relevance. This upper limit set also allowed for filtering out of the largest firms and presumably eliminated some of the typical organisational inertia characteristics of large firms, which may bias EO indicators (Jantunen et al., 2005).

By using these selection criteria, the surveyed population was based on a comprehensive membership list of businesses operating in the Johannesburg area. All potential respondents were based in the Gauteng province, the economic hub of South Africa, which has the highest number of businesses and accounts for almost half of all enterprises in South Africa. The sampling frame was identified from the Johannesburg Chamber of Commerce and Industry (JCCI) database of businesses operating in the greater Johannesburg area (JCCI, 2008). A wide range of businesses, which included various industry sectors, were sampled. The population of this database is approximately 1600 firms. Based on eligibility criteria and employing a non-probability judgemental sampling technique, 755 potential respondents were surveyed Judgemental sampling is used when a sample is selected where certain judgements are made on the overall population. The frame selection process for this study can be viewed as a trade-off between practical considerations on the one hand and the demands of randomisation and generalisability on the other. Davidsson (2004) suggests that firms are heterogeneous along many dimensions, and that one should acknowledge the heterogeneity, i.e. allow for samples to have reasonable and balanced representation of different kinds of valid empirical manifestations of the theoretical concept 'firm'. Consequently, due to the heterogeneity of the different industry sectors sampled, the generalisability of this study is strengthened. Moreover, the important issue concerning sampling, in general, is not statistical but theoretical representativeness, i.e. the elements in the sample should represent the type of phenomenon that the theory makes statements about (Davidsson, 2004).

\section{Research procedure}

A compact disk of the total membership database from the JCCI was obtained, and the necessary access codes received, allowing access to the total population with their respective contact details. Once permission was obtained from the JCCI offices, questionnaires were solicited electronically with periodic reminder telephone calls. A number of respondents indicated that not all items were applicable to their situation and subsequently these responses were assigned as missing data. Based on these procedures and the suitability of respondents,

TABLE

Sample distribution by class of industry sectors

\begin{tabular}{llll}
\hline Industry Sector & $\boldsymbol{N}$ & $\%$ & Cumulative \% \\
\hline Health \& Personal Care Products & 27 & 11.7 & 11.7 \\
Computers/Office Machinery Electronics & 24 & 10.4 & 22.2 \\
Food Products & 23 & 10 & 32.2 \\
Leisure Goods & 16 & 7 & 39.1 \\
Industrial, Commercial Machinery & 16 & 7 & 46.1 \\
Leather/Rubber/Plastics Materials & 15 & 6.5 & 52.6 \\
Others (Music Entertainment /Aerospace) & 13 & 5.7 & 58.3 \\
Metal Products: Non-ferrous & 13 & 5.7 & 63.9 \\
Beverages \& Tobacco & 13 & 5.7 & 69.6 \\
Banking Industry/Services & 12 & 5.2 & 74.8 \\
Forestry Products \& Paper Furniture & 11 & 4.8 & 79.6 \\
Insurance & 8 & 3.5 & 83 \\
Instruments \& Control Devices, Medical & 7 & 3 & 86.1 \\
Metal Products: Ferrous & 6 & 2.6 & 88.7 \\
Textiles \& Apparel & 5 & 2.2 & 90.9 \\
Specialty Chemicals & 5 & 2.2 & 93 \\
Recruitment & 5 & 2.2 & 95.2 \\
Printing \& Publishing & 4 & 1.7 & 97 \\
Pharmaceuticals & 4 & 1.7 & 98.7 \\
Automobiles & 3 & 1.3 & 1.3 \\
\hline Total & $\mathbf{2 3 0}$ & $\mathbf{1 0 0 \%}$ & $\mathbf{1 0 0 \%}$ \\
\hline
\end{tabular}


TABLE 2

Sample characteristics

\begin{tabular}{lll}
\hline \multicolumn{3}{c}{ Sample characteristics } \\
\hline Firm Age & $\boldsymbol{N}$ & $\mathbf{\%}$ \\
\hline+20 years & 111 & 48.3 \\
$10-19$ years & 52 & 22.6 \\
$7-10$ years & 35 & 15.2 \\
$3-7$ years & 29 & 12.6 \\
$<3$ years & 3 & 1.3 \\
\hline Total & $\mathbf{2 3 0}$ & $\mathbf{1 0 0 \%}$ \\
\hline
\end{tabular}

TABLE 3

Sample characteristics

\begin{tabular}{lll}
\hline Firm Size & $\boldsymbol{N}$ & $\%$ \\
\hline+99 employees & 131 & 56.5 \\
$50-99$ & 44 & 19 \\
$21-49$ & 33 & 14.2 \\
$11-20$ & 15 & 6.5 \\
$<10$ & 7 & 3 \\
\hline Total & $\mathbf{2 3 0}$ & $\mathbf{1 0 0 \%}$ \\
\hline
\end{tabular}

230 usable responses were generated as the final sample $(30.5 \%$ response rate).

\section{Statistical analysis}

Instruments were subjected to principal component factor analysis; the results that were obtained are discussed in the next section in terms of factor loadings and reliability. Descriptive statistics were calculated in terms of mean scores and deviations in scores. The hypotheses were tested using correlational analysis, with their significance reported in terms of Pearson correlation coefficients.

\section{RESULTS}

\section{Sample characteristics}

Sample distribution by industry sector is reflected in Table 1 . Certain industries were clearly under-sampled and others over-sampled. Nonetheless, based on the heterogeneity of the several different industry sectors sampled, the generalisability of this study is strengthened.

Firm demographics are represented in Tables 2 and 3. Sampled firms were generally mature in age, with relatively high employee numbers.

\section{Reliability and factor analysis}

With regard to testing the scales for internal consistency, items measuring EO and TO rendered satisfactory Cronbach's alpha values of 0.793 and 0.749 , respectively. In terms of the environmental scales, the two distinct sub-scales of environmental hostility and dynamism produced satisfactory Cronbach's alpha values of 0.742 and 0.717 respectively.
To test for scale validity, factor analysis using Bartlett's test of sphericity was employed, and a significant $(0.000)$ chi-square of 638.228 at 36 degrees of freedom (df) was produced. This test calculates the determinate of the matrix of the sums of products and cross-products from the inter-correlation matrix. The Kaiser Meyer Olkin (KMO) measure of sampling adequacy produced a result of 0.823 (KMO values of 0.90 to 1.00 indicate a high degree of common variance). Factor loadings greater than or equal to .30 were regarded as significant, and factors with eigenvalues greater than 1 (based on scree tests and Kaiser's stopping rule) (Cooper \& Emory, 1995) were used to decide on the optimal number of factors to retain. The items used to measure the EO dimensions were factored using the principal axis factoring method, resulting in one factor (eigenvalue $\lambda=$ 4.564 ) with a communality factor of $57 \%$. Refer to Table 4 for factor loadings and Cronbach's alpha values.

For the environmental hostility and dynamism sub-scales, communalities were calculated by way of principal axis factoring and using Varimax rotation - converging in seven iterations - two factors with eigenvalues of 4.679 and 1.254 indicated suitable factor loadings. These two factors reflect the distinct sub-scales of environmental hostility and dynamism. These factor loadings and Cronbach's alpha values are consolidated with the descriptive results in Table 6.

\section{Descriptive statistics}

By applying tests for normality, and by calculating the Kolmogorov-Smirnov and Shapiro-Wilk statistics, test scores $(0.07)$ indicated that normality was not violated.

Descriptive analysis revealed that for the EO scale, above midpoint (3.5) scores across items were prevalent. A relatively high average score emerges for this scale, suggesting that firms have medium to high levels of EO, as captured through the dimensions of innovativeness, proactiveness and risk-taking. In a few instances the variance, as measured by the standard deviation, is relatively high, as the score for the first variable exceeds a value of two. This indicates that there is a lot of variation among firms with regard to some of the EO items. See Table 5 for the descriptive statistical results.

For descriptives on the environmental scales, both dynamism and hostility had above mid-point (3.5) scores, although many only just exceeded this mid-point score (see Table 7). This means that firms perceive environmental hostility and dynamism to be slightly above average. However, managers' perceptions of their environments do not always reflect the objective qualities of their markets and industries. Such mismatches may arise from ineffective competitive analyses, poor environmental analyses, cognitive biases or managerial hubris (Zahra \& Bogner, 1999).

\section{Firm clustering}

Consistent with previous studies, cluster analysis was used to empirically delineate between firms with different types

TABLE 4

Factor Matrix for EO scale: Reliability and Validity

\begin{tabular}{llll}
\hline Item & Factor Loading & Cronbach's Alpha & Item Correlation \\
\hline In general, the top managers of my company ... & 0.782 & 0.883 & 0.390 \\
In dealing with its competitors, my company ... & 0.764 & 0.883 & 0.655 \\
How many lines of new products has your company ... & 0.741 & 0.876 & 0.757 \\
Changes in product or service lines have been ... & 0.736 & 0.874 & 0.361 \\
In general, the top managers of my company have ... & 0.727 & 0.881 & 0.875 \\
In dealing with its competitors, my company ... & 0.698 & 0.888 & 0.543 \\
In dealing with its competitors, my company ... & 0.688 & 0.873 & 0.600 \\
In general, the top managers of my company favour ... & 0.669 & 0.872 & 0.587 \\
How many lines of new products has your company ... & 0.647 & 0.661 \\
\hline
\end{tabular}

How many lines of new products has your company

: Principal Axis Factoring

Notes: Item wording has been abbreviated. Extraction and Rotation Method: Principal Axis Factoring.
One factor extracted. Varimax with Kaiser Rotation Normalization. Rotation converged in 4 iterations. 
TABLE 5

Descriptive statistics of entrepreneurial orientation

\begin{tabular}{|c|c|c|c|c|}
\hline Item & $N$ & Mean & s.d. & s.e. \\
\hline In general, the top managers of my... & 229 & 3.698 & 2.004 & 0.095 \\
\hline In dealing with its competitors, my... & 229 & 4.512 & 1.802 & 0.102 \\
\hline How many lines of new products has ... & 229 & 3.803 & 1.783 & 0.099 \\
\hline Changes in product or service lines ... & 229 & 4.524 & 1.465 & 0.104 \\
\hline In general, the top managers of my... & 229 & 4.725 & 1.511 & 0.109 \\
\hline In dealing with its competitors, my ... & 229 & 4.787 & 1.602 & 0.098 \\
\hline In dealing with its competitors, my ... & 229 & 4.821 & 1.676 & 0.116 \\
\hline In general, the top managers of my... & 229 & 4.299 & 1.523 & 0.117 \\
\hline How many lines of new products has. & 229 & 4.222 & 1.461 & 0.130 \\
\hline
\end{tabular}

s.e. $=$ standard error

TABLE 6

Factor Matrix for environmental scales: Reliability and Validity

\begin{tabular}{lll}
\hline Item & Factor Loadings & Cronbach's Alpha \\
\hline Environmental hostility & & Item Correlation \\
The failure rate of firms in my industry is high. & 0.754 & 0.623 \\
My industry is very risky, one bad decision could ... & 0.612 & 0.650 \\
Competitive intensity is high in my industry. & 0.726 & 0.656 \\
Customer loyalty is low in my industry. & 0.339 & 0.687 \\
Severe price wars are characteristic of my industry. & 0.658 & 0.727 \\
Low profit margins are characteristic of my industry. & 0.530 & 0.627 \\
Environmental dynamism & & 0.619 \\
Actions of competitors are easy to predict. & 0.708 & 0.714 \\
The set of competitors is relatively constant. & 0.730 & 0.715 \\
Product demand is easy to forecast. & 0.678 & 0.646 \\
Customer requirements are easy to forecast. & 0.566 & 0.645 \\
My industry is very stable with every little change.... & 0.514 & 0.534 \\
\hline
\end{tabular}

Notes: Item wording has been abbreviated. Extraction and Rotation Method: Principal Axis Factoring

Two factors extracted. Varimax with Kaiser Rotation Normalization. Rotation converged in 7 iterations.

of TO (Galbraith, Rodriquez \& DeNoble, 2008). The process of clustering the data set was performed with the use of clustering algorithms that identified similar characteristics in the data set and then filtered/partitioned firms into the three clusters. Examining the difference in categorical values of the TO variables $(p<01)$, the first cluster clearly reflected a grouping of firms with a 'first mover' TO (21.74 \% of sample), while the second cluster appeared to have more of an 'innovator' TO $(9.57$ $\%$ of the sample), and the third cluster, which contained the majority of responses, had a 'practitioner' TO $(68.69 \%$ of the sample).

\section{Multivariate analyses}

To evaluate the hypothesised relationships between the variables, correlational analysis was employed. It has been suggested that the correlation significance should be checked before embarking on regressions (Cooper \& Emory, 1995). For the correlation matrix, refer to Table 8, in which the Pearson correlation coefficients are reported, with the values in the second line of each row indicating the $p$-values. According to Cohen and Holliday (1998), a multiple correlation coefficient of 0.7 or above indicates a high relationship. Anastasia and Urbani (1997) maintain that it should be high enough to be statistically significant at the 0.05 and 0.01 levels.

Based on the findings represented in Table 8, hypothesis 1 cannot be confirmed, as EO and TO are not significantly correlated. However, both EO and TO are highly correlated with environmental hostility and dynamism. In fact, EO has almost a perfect correlation with both environmental measures. This suggests that a variance in EO is highly attributable to a change in either environmental dynamism or hostility.
To further explore associations with any of the control variables, firm age was juxtaposed against EO, TO and a combined environmental dynamism or hostility score. All variables dipped in the 7-10 year category (not shown). A plausible explanation for this is that firms mimic the classical venture life cycle. When firms enter a late growth phase and the mature phase, a period of consolidation occurs in which TO and/or EO and environmental factors drop off. When firms move into the rejuvenation phase (after 10 years), an increase in $\mathrm{TO}$ and/or EO and environmental factors is evident.

\section{DISCUSSION}

The purpose of this study was to test the relationship between $\mathrm{EO}$ and TO by measuring how environmental factors might be associated with each orientation type. Contributing to literature by building on and complementing existing studies, this study emphasised the challenge and opportunity for firms in emerging economies to adopt technology and act entrepreneurially, which can optimise and maximise developmental efforts.

In line with contemporary research, it was expected that the entrepreneurial and technology orientations of firms will be significantly associated with each other (hypothesis 1) as well as with perceived environmental dynamism and hostility (hypothesis 2). Contrary to expectations, no evidence for hypothesis 1 could be detected. Nonetheless, the lack of significant associations between $\mathrm{EO}$ and $\mathrm{TO}$ is not trivial for exploratory research in a new domain such as entrepreneurship, particularly in the context of an emerging country. On the other hand, the significant and positive correlations between $\mathrm{EO}$ and environmental hostility and dynamism provide unequivocal 
TABLE 7

Descriptives for environmental hostility and dynamism

\begin{tabular}{|c|c|c|c|c|}
\hline Item & $N$ & Mean & s.d. & s.e. \\
\hline \multicolumn{5}{|l|}{ Environmental hostility } \\
\hline The failure rate of firms in my industry is high. & 229 & 3.594 & 1.174 & 0.114 \\
\hline My industry is very risky, one bad decision could ... & 229 & 3.755 & 1.664 & 0.111 \\
\hline Competitive intensity is high in my industry. & 229 & 3.365 & 1.663 & 0.121 \\
\hline Customer loyalty is low in my industry. & 229 & 4.584 & 1.855 & 0.120 \\
\hline Severe price wars are characteristic of my industry. & 229 & 3.676 & 1.736 & 0.128 \\
\hline Low profit margins are characteristic of my industry. & 229 & 4.365 & 1.903 & 0.115 \\
\hline \multicolumn{5}{|l|}{ Environmental dynamism } \\
\hline Actions of competitors are easy to predict. & 229 & 3.694 & 1.675 & 0.102 \\
\hline The set of competitors is relatively constant. & 229 & 3.784 & 1.746 & 0.127 \\
\hline Product demand is easy to forecast. & 229 & 3.589 & 1.737 & 0.110 \\
\hline Customer requirements are easy to forecast. & 229 & 3.551 & 1.825 & 0.109 \\
\hline My industry is very stable with every little change $\ldots$. & 229 & 3.672 & 1.827 & 0.119 \\
\hline
\end{tabular}

s.d. = standard deviation

s.e. $=$ standard error

TABLE 8

Correlation Matrix for EO, TO and Environmental Hostility and Dynamism

\begin{tabular}{|c|c|c|c|c|c|}
\hline \multicolumn{2}{|l|}{ Factors } & \multirow{2}{*}{$\begin{array}{l}\text { Entrepreneurial } \\
\text { Orientation (EO) }\end{array}$} & \multirow{2}{*}{$\begin{array}{l}\text { Technology } \\
\text { Orientation (TO) }\end{array}$} & \multirow{2}{*}{$\begin{array}{l}\text { Environmental } \\
\text { Dynamism (ED) }\end{array}$} & \multirow{2}{*}{$\begin{array}{l}\text { Environmental } \\
\text { Hostility (EH) }\end{array}$} \\
\hline & & & & & \\
\hline \multirow[t]{4}{*}{ EO } & Pearsons & 1.000 & & & \\
\hline & Correlation & & & & \\
\hline & Sig. (2-tailed) & $0.034^{* *}$ & & & \\
\hline & $N$ & 229 & & & \\
\hline \multirow[t]{4}{*}{ то } & Pearsons & 0.483 & 1.000 & & \\
\hline & Correlation & & & & \\
\hline & Sig. (2-tailed) & $0.002^{*}$ & $0.001^{*}$ & & \\
\hline & $N$ & 229 & 299 & & \\
\hline \multirow[t]{4}{*}{ ED } & Pearsons & 0.954 & 0.723 & 1.000 & \\
\hline & Correlation & & & & \\
\hline & Sig. (2-tailed) & $0.037^{\star \star}$ & $0.044^{\star *}$ & 0.078 & \\
\hline & $N$ & 229 & 229 & 229 & \\
\hline \multirow[t]{4}{*}{$\mathrm{EH}$} & Pearsons & 0.964 & 0.696 & 0.999 & 1.000 \\
\hline & Correlation & & & & \\
\hline & Sig. (2-tailed) & $0.025^{\star *}$ & $0.032^{* *}$ & $0.012^{\star \star}$ & $0.002^{*}$ \\
\hline & $N$ & 229 & 229 & 229 & 229 \\
\hline
\end{tabular}

* Correlation is significant at the 0.01 level (2-tailed), ${ }^{* *}$ Correlation is significant at the 0.05 level (2-tailed).

support for hypothesis 2. The association between $\mathrm{TO}$ and hostility and dynamism is less strong, yet significant at the 0.05 level. These findings resonate with research which has found that a key part of technology and innovation strategies is the interaction of that strategy with the venture's external environment (Zahra \& Bogner, 1999).

Another plausible explanation for the strong and positive associations is that, when the environment is characterised by complexity and dynamism, firms have to anticipate future scenarios and develop proactive $\mathrm{EO}$ and $\mathrm{TO}$ strategies in ambiguous and unstructured surroundings (Allen \& Stearns, 2004).

This study also re-establishes scale reliability and validity in the context of an emerging country. Concerns have been expressed as to whether imported instruments would stand up to validation across countries (Nkosi \& Roodt, 2004; Van de Vijver \& Rothmann, 2004). This study has found support for the same factor structures across the measures used.

Research on firm innovation in the African context may be considered valuable, as very few empirical studies that have been conducted previously focus on innovation and technology in the context of an emerging country. The majority of research on firm innovation has been conducted in the United States and subsequently the generalisability of TO and in particular EO remains limited, because of a western proclivity for limited cross-cultural testing (Antoncic \& Hisrich, 2001). Although studies (such as Kreiser et al., 2002) have confirmed the crosscultural validity of the EO scale, samples typically exclude African countries. Therefore an empirical study of this nature is potentially valuable considering that technology and innovation and their effective diffusion are central and critical to the growth of economic output, productivity and employment. Additionally, the importance of international entrepreneurship justifies that constructs are tested for relevance in the context of emerging countries as well (Jantunen et al., 2005; Ulijn, Nagel \& Liang, 2001).

The centrality of the TO and EO constructs is not new; nevertheless, this study adds to a better understanding of these strategic orientations in a non-western context, which in turn enhances their generalisability. The study also offers some solutions towards understanding how TO and EO may promote firm innovation, which encourages the diffusion, adoption and application of the very latest technologies. This is particularly relevant in cases where a lot of potential exists in developing countries to 'import and adapt' technologies 
developed in industrialised countries (Von Broembsen, Wood \& Herrington, 2005)

A deep and thorough understanding of EO, TO and environmental conditions is important not only for academic purposes but also because the subject has salience for practitioners and policy makers. These implications relate to the profitability and competitiveness of the firm as well as to the overall economic performance of industry and the national economy (Dorf \& Byers, 2008). Businesses that incorporate innovation into their vision by relying on entrepreneurial strategies and actions understand that innovation is at the core of an entrepreneurial organisation. It is around this core that other elements of the organisation, such as strategy, management style and structure, are built. Corporate environments supportive of entrepreneurship must provide appropriate reward systems, top management support, explicit goals and appropriate organisational values, which signal to employees that entrepreneurial behaviour action is desirable.

Moreover, government programmes and incentives could focus on established firms with higher levels of EO and TO rather than on potential individual entrepreneurs, since in an emerging-country context, institutional conditions need to be strengthened first before entrepreneurship can flourish (Minniti, Bygrave \& Autio, 2005). Around the world, most governments have recognised the potential in high technology and have begun nurturing this industry through support institutions. They acknowledge the importance of intellectual capital in growing knowledge economies and create conditions that foster innovation.

\section{Limitations and future research}

Because environmental conditions vary significantly from one industry to another (Dess \& Beard, 1984) and because the nature of the environmental characteristics is inextricably linked to the stage of the industry's evolution (Zahra \& Bogner, 1999), controls for these variations are necessary in future studies. Moreover, in some contexts there may be differences in how the environmental dimensions relate to $\mathrm{EO}$ and $\mathrm{TO}$. Findings in this study may also be related to the influence of other contingencies not incorporated or to measurement issues unobserved. A further limitation of this study is that a cross-sectional study loses the dynamic aspects of EO and $\mathrm{TO}$, particularly in hostile and dynamic environments, which prevents conclusions about causal relationships to be drawn.

\section{Conclusion}

Entrepreneurship can provide direction to the company's entire operation, serves as an integral component of a firm's strategy and may function as the core component of corporate strategy (Covin \& Slevin, 1997). Each of the EO dimensions innovativeness, proactiveness and risk-taking - is useful for predicting the success of business, which may be contingent on the environment. Managers can establish the impact of environmental dynamism and hostility on EO and TO and explore the effect of these factors on various performance indicators. Indeed managers need to adopt a contingency perspective on how environmental and organisational factors moderate, mediate or interact with $\mathrm{TO}$ and EO to enhance business performance.

\section{REFERENCES}

Allen, K., \& Stearns, T. (2004). Technology entrepreneurs. In W.B. Gartner, K.G. Shaver, N.M. Carter \& P.D. Reynolds (Eds.), Handbook of entrepreneurial dynamics. The process of business creation (pp. 438-447). Thousand Oaks, CA: Sage.

Aloulou, W., \& Faylolle, A. (2005). A conceptual approach of entrepreneurial orientation within small business context. Journal of Enterprising Culture, 13, 21-45.

Anastasia, A., \& Urbani, S. (1997). Psychological testing. (7th edn.) New Jersey: Prentice-Hall.
Antoncic, B. (2006). Impacts of diversification and corporate entrepreneurship strategy making on growth and profitability: A normative model. Journal of Enterprising Culture, 14, 49-63.

Antoncic, B., \& Hisrich, R.D. (2001). Intrapreneurship: Construct refinement and cross cultural validation. Journal of Business Venturing, 16, 495-527.

Asia Africa Intelligence Wire. (2005, 14 November). Promoting technopreneurship.

Autio, E. (2005). Report on high-expectancy entrepreneurship. Global Entrepreneurship Monitor Report. Babson: HEC Lausanne.

Bhuian, S.N., Menguc, B., \& Bell, S.J. (2005). Just entrepreneurial enough: The moderating effect of entrepreneurship on the relationship between market orientation and performance. Journal of Business Research, 58, 9-17.

Bosma, N., Jones, K., Autio, E., \& Levie, J. (2007). Global Entrepreneurship Monitor Executive Report. London: London Business School.

Brown, T., Davidsson, P., \& Wiklund, J. (2001). An operalization of Stevenson's conceptualization of entrepreneurship as opportunity-based firm behavior. Strategic Management Journal, 22, 953-968.

Chen, J., He, Y.B., \& Jin, X. (2008). A study on the factors that influence the fitness between technology strategy and corporate strategy. International Journal of Innovation and Technology Management, 5, 81-103.

Cohen, L., \& Holliday, M. (1998). Practical statistics for students. London: Paul Chapman.

Cooper, R.D., \& Emory, C.W. (1995). Business research methods. (5th edn.). Chicago: Irwin.

Conway, C. (2008). Nanotechnology and biotechnology futures. The International Journal of Entrepreneurship and Innovation 19, 69-70.

Covin, J.G., \& Slevin, D.P. (1989). Strategic planning of small firms in hostile and benign environments. Strategic Management Journal, 10, 75-87.

Covin, J.G., \& Slevin, D.P. (1991). A conceptual model of entrepreneurship as firm behavior. Entrepreneurship Theory and Practice, 16, 7-26.

Covin, J.G., \& Slevin, D.P. (1997). High growth transitions: Theoretical perspectives and suggested directions. In D.L. Sexton, \& R.W. Smilor (Eds.), Entrepreneurship 2000 (pp. 99126). Chicago: Kaplan Publishing.

Covin, J.G., Green, K.M., \& Slevin, D.P. (2006). Strategic process effects on the entrepreneurial orientation-sales growth rate relationship. Entrepreneurship Theory and Practice, 30, $57-81$.

Davidsson, P. (2004). Researching entrepreneurship. International studies in entrepreneurship. New York: Springer.

Dess, G.G., \& Beard, D.W. (1984). Dimensions of organizational task environment. Administrative Staff Quarterly, 29, 5273.

Dess, G.G., Ireland, R.D., Zahra, S.A., Floyd, S.W., Janney, J.J., \& Lane, P.J. (2003). Emerging issues in corporate entrepreneurship. Journal of Management, 29, 351378.

Dorf, R.C., \& Byers, T.H. (2008). New technology ventures. (2nd edn.). Boston: McGraw-Hill.

Drucker, P. (1979). The practice of management. London: Pan Books.

Fiet, J.O., Norton, B., \& Clouse, V. (2002). A test model of discovery by technically trained employees. Frontiers of Entrepreneurship Research XVII-SI. Wellesley, MA: Babson College.

Foba, T.W.L., \& De Villiers, D. (2007). The integration of intrapreneurship into a performance management model. SA Journal of Human Resource Management, 5(2), $1-8$.

Foo, C., \& Foo, C. (2000). Socialisation of technopreneurism Towards symbiosis in corporate innovation and technology strategy. Technovation, 20, 551-663.

Galbraith, C.S., Rodriquez, C.L., \& Denoble, A.F. (2008). SME competitive strategy and location behaviour: An exploratory 
study of high-technology manufacturing. Journal of Small Business Management, 46, 183-202.

Gartner, W.B., Shaver, K.G., Carter, N.M., \& Reynolds, P.D. (2004). Handbook of entrepreneurial dynamics: the process of business creation. Thousand Oaks, CA: Sage.

Goel, S., Gonzalez-Moreno A., \& Saez-Martines, F.J. (2003). Performance implications of co-alignment of business and technological innovation strategy. The International Journal of Entrepreneurship and Innovation, 4, 213-224.

Guan, J., \& Liu, J. (2007). Integrated innovations between technology and organisation. International Journal of Innovation and Technology Management, 4, 415432.

Hamel, G. (2000). Leading the revolution. Cambridge, MA: Harvard University Press.

Hornsby, S.J., Kuratko, D.F., \& Zahra, S.A. (2002). Middle managers' perception of the internal environment for corporate entrepreneurship: Assessing a measurement scale. Journal of Business Venturing, 17, 253-273.

Jantunen, A.K., Puumalainen, S., Saarenketo, S., \& Kylaheiko, K. (2005). Entrepreneurial orientation, dynamic capabilities and international performance. Journal of International Entrepreneurship, 3, 223-243.

Khandwalla, P.N. (1977). The design of organizations. New York: Harcourt.

Knight, G.A. (1997). Cross-cultural reliability and validity of a scale to measure firm entrepreneurial orientation. Journal of Business Venturing, 12, 213-225.

Kourilsky, M.L., \& Walstad, W.B. (2002). The early environment and schooling experiences of high-technology entrepreneurs: Insights for entrepreneurship education. International Journal of Entrepreneurship Education, 1, 87106.

Kreiser, P.M., Marino, L.D., \& Weaver, M.K. (2002). Assessing the psychometric properties of the entrepreneurial orientation scale: A multi country analysis. Entrepreneurship Theory and Practice, 26 (Spring), 71-94.

Kuratko, D.F. (2002). Corporate entrepreneurship. Mason, OH: Harcourt College Publishers.

Kuratko, D.F., \& Audretsch, D.B. (2009). Strategic entrepreneurship: Exploring different perspectives of an emerging concept. Entrepreneurship Theory and Practice, $33(1), 1-17$.

Kuratko, D.F., Ireland, R.D., \& Hornsby, J.S. (2001). Improving firm performance through entrepreneurial actions: Corporate entrepreneurship strategy. Academy of Management, 15, 60-71.

Lee, C., Lee, K., \& Penning, J.M. (2001). Internal capabilities, external networks, and performance: A study on technology-based ventures. Strategic Management Journal, $22,615-640$.

Lee, S.H., \& Wong, P.K. (2004). An exploratory study of technopreneurial intentions: A career anchor perspective. Journal of Business Venturing, 19, 7-28.

Lumpkin, G.T., \& Dess, G.G. (1996). Clarifying the entrepreneurial orientation construct and linking it to performance. Academy of Management Review, 21, 135166.

Lumpkin, G.T., \& Dess, G.G. (2001). Linking two dimensions of entrepreneurial orientation to firm performance: The moderating role of environment and industry life cycle. Journal of Business Venturing, 16, 429-451.

McGuigan, M., \& Henderson, J. (2005). Organizational strategic innovation: How is government policy helping? International Journal of Innovation and Technology Management, 2, 197215.

Miller, D., \& Friesen, P.H. (1983). Innovation in conservative and entrepreneurial firms: Two models of strategic momentum. Strategic Management Journal, 3, 1-25.

Minniti, M., Bygrave, W.D., \& Autio, E. (2005). Global Entrepreneurship Monitor Executive Report 2005. London: London School of Economics.

Morris, M.H., Kuratko, D.F., \& Covin, J.G. (2008). Corporate entrepreneurship and innovation. Cincinnati: Thomson/ Southwestern.
Myers, S., \& Marquis, D.G. (1969). Successful industrial innovation. Washington, DC: National Science Foundation

Nkosi, T.J., \& Roodt, G. (2004). An assessment of bias and fairness of the culture assessment instrument. South African Journal of Human Resource Management, 2, 24-36.

Park, S., \& Bae, Z.T. (2004). New venture strategies in a developing country: Identifying a typology and examining growth patterns through case studies. Journal of Business Venturing, 19, 81-105.

Porter, M. (1985). Competitive advantage. New York: Free Press.

Pownall, I., \& Lawson, V. (2005). A regional entrepreneurial orientation (REO) model for a northern English town. Journal of Enterprising Culture, 13, 295-331.

Rwigema, H., Urban, B., \& Venter, R. (2008). Entrepreneurship theory in practice. Cape Town: Oxford University Press.

Schindehutte, M., Morris, M.H., \& Kocak, A. (2008). Understanding market-driving behavior: The role of entrepreneurship. Journal of Small Business Management, 46, $4-26$.

Schumpeter, J.A. (1934). The theory of economic development. Cambridge, MA: Harvard University Press.

Shrader, R., \& Siegel, D.S. (2007). Assessing the relationship between human capital and firm performance: Evidence from technology-based new ventures. Entrepreneurship Theory and Practice, 31, 893-909.

Stevenson, H.H. (1983). A perspective on entrepreneurship. Harvard Business School Working Paper, 9, 384-131.

Tang, L., \& Koveos, P.E. (2004). Venture entrepreneurship, innovation entrepreneurship, and economic growth. Journal of Developmental Entrepreneurship, 9, 161-171.

Ulijn, J., Nagel, A., \& Liang, T.W. (2001). The impact of national, corporate and professional cultures on innovation: German and Dutch firms compared. Journal of Enterprising Culture, $9(1), 21-52$

Urban, B. (2008). Entrepreneurship orientation in a developing country context: Juxtapositions with South Africa's Innovation Index. Journal of Developmental Entrepreneurship, 13(4), 425-443.

Van de Vijver, F.J.R., \& Rothmann, S. (2004). Assessment in multicultural groups: The South African case. SA Journal of Industrial Psychology, 30, 1-7.

Venkataraman, S. (2003). Regional transformation through technological entrepreneurship. Journal of Business Venturing, 19,153-167.

Von Broembsen, M., Wood, E., \& Herrington, M. (2005). Global Entrepreneurship Monitor, South African Report 2005. Cape Town: University of Cape Town Graduate School of Business.

Wang, C.L. (2008). Entrepreneurial orientation, learning orientation, and firm performance. Entrepreneurship Theory and Practice, 32(4) 635-656.

Wiklund, J. (1999). The sustainability of the entrepreneurial orientation-performance relationship. Entrepreneurship Theory and Practice, 24, 37-50.

Wiklund, J., \& Shepherd, D. (2003). Knowledge based resources, entrepreneurial orientation, and the performance of small and medium sized businesses. Strategic Management Journal, 24, 1307-1314.

Wong, W.K., Cheung, H.M., \& Venuvinod, P.K. (2005). Individual entrepreneurial characteristics and entrepreneurial success potential. International Journal of Innovation and Technology Management, 3, 277-292.

Zahra, S. (1993). A conceptual model of entrepreneurship as firm behaviour: A critique and extension. Entrepreneurship Theory and Practice, 16, 5-21.

Zahra, S.A., \& Covin, J.G. (1995). Contextual influences on the corporate entrepreneurship- performance relationship: A longitudinal analysis. Journal of Business Venturing, 10, 43-58.

Zahra, S.A., \& Bogner, W.C. (1999). Technology and software new ventures performance: Exploring the moderating effect of the competitive environment. Journal of Business Venturing, 15, 135-173. 